\title{
Fabrication of Silicon Nitride Thick Coatings by Reactive RF Plasma Spraying*1
}

\author{
Motohiro Yamada*2, Tatsuya Inamoto*2, Masahiro Fukumoto and Toshiaki Yasui \\ Department of Production Systems Engineering, Toyohashi University of Technology, Toyohashi 441-8580, Japan
}

Silicon nitride $\left(\mathrm{Si}_{3} \mathrm{~N}_{4}\right)$ is one of the attractive ceramics in respect of its excellent properties both in wear and thermal shock resistance. In this research, $\mathrm{Si}_{3} \mathrm{~N}_{4}$ thick coatings were fabricated by reactive $\mathrm{RF}$ (Radio Frequency) plasma spray process, and a reactive plasma spraying, in which metal element reacts with surrounding active species in plasma, has been considered to be an useful way for the formation of non-oxide ceramics coatings. Spraying with $\mathrm{Ar} / \mathrm{N}_{2}$ mixed gas was not effective for the fabrication of $\mathrm{Si}_{3} \mathrm{~N}_{4}$ coatings. Hydrogen addition as a reactive plasma gas improved the nitridation significantly. $\mathrm{Si}_{3} \mathrm{~N}_{4}$ content in the coatings could be controlled by changing $\mathrm{N}_{2}$ and/or $\mathrm{H}_{2}$ fraction in plasma gas. Hardness of the coatings obtained increased with increasing $\mathrm{Si}_{3} \mathrm{~N}_{4}$ content in the coating. Nitriding reaction of $\mathrm{Si}$ in reactive $\mathrm{RF}$ plasma spraying was promoted in the liquid phase of Si after deposited onto the substrate.

(Received July 30, 2004; Accepted September 17, 2004)

Keywords: silicon nitride; nitride ceramics; thick coating; reactive spraying; radio frequency plasma; nitriding process

\section{Introduction}

In recent years, surface modification process has been receiving great interest for fabricating protection coatings on the structural materials. Nitride ceramics have excellent properties in many aspects. Especially for high temperature and wear resistance applications, ${ }^{1,2)}$ nitride ceramics might contribute to the various structural parts. For example, titanium nitride ( $\mathrm{TiN}$ ) has excellent mechanical properties for wear resistance applications. ${ }^{3)}$ Formation of these nitride ceramics coatings has been developed using CVD, PVD or thermal spray processes. ${ }^{4-8)}$ Among these, silicon nitride $\left(\mathrm{Si}_{3} \mathrm{~N}_{4}\right)$ can be characterized as an excellent candidate for the structural components. First of all, $\mathrm{Si}_{3} \mathrm{~N}_{4}$ has a quite high resistance of thermal shock. ${ }^{9)}$ In addition, it has a good chemical stability at fairly high temperature regions, high resistance of wear and corrosion, low density $\left(3190 \mathrm{kgm}^{-3}\right)$, high hardness $(1800 \mathrm{HV})$ and high toughness. ${ }^{10-12)}$ Thus, $\mathrm{Si}_{3} \mathrm{~N}_{4}$ is contributed to the several applications. ${ }^{9)}$ Hereby, fabrication of $\mathrm{Si}_{3} \mathrm{~N}_{4}$ thick coatings might be useful for the structural components.

Usually, $\mathrm{Si}_{3} \mathrm{~N}_{4}$ coatings have been produced by $\mathrm{PVD}^{12)}$ or $\mathrm{CVD}^{13)}$ processes. It is possible to form dense and homogeneous coatings by these processes. However, it is difficult to apply the formation of thick coatings, which might contribute to the structural parts, because of their low deposition rates. On the other hand, thick coatings can be easily formed by thermal spray process. However, it is difficult to fabricate $\mathrm{Si}_{3} \mathrm{~N}_{4}$ coatings by conventional thermal spray processes like APS (Atmospheric Plasma Spray), LPPS (Low Pressure Plasma Spray) or HVOF (High Velocity Oxide Fuel) etc. The difficulty is due to a decomposition of $\mathrm{Si}_{3} \mathrm{~N}_{4}$ under a high temperature $(2173 \mathrm{~K})$, and the nitrides easily transforms into oxide and hereby losing their excellent properties. ${ }^{14-16)}$ On the other hand, reactive plasma spraying, in which metal element reacts with surrounding active species in plasma, has been considered to be an useful process for the formation of nitride ceramics thick coatings. The reactive spraying process

\footnotetext{
${ }^{*}$ Paper was Presented at the Fall Meeting of the Japan Thermal Spraying Society, held in Okayama on November 10, 2003.

${ }^{* 2}$ Graduate Students, Toyohashi University of Technology
}

has been developed using a DC plasma, ${ }^{8)}$ RF plasma $^{6)}$ or laser ${ }^{17)}$ as the reactive heat source. Among these, RF plasma flame is characterized by high temperature and low velocity. These characteristics of RF plasma are supposed to provide much reaction chance of raw materials with active species in plasma.

In this study, feasibility of fabricating $\mathrm{Si}_{3} \mathrm{~N}_{4}$ thick coatings by reactive RF plasma spray process was investigated. Furthermore, nitriding of Si in the process was fundamentally investigated for controlling the nitridation in plasma. Mechanical property of the coatings obtained by this process was evaluated by micro Vickers hardness test.

\section{Experimental Procedure}

Row material used was Si powder (96\%) with a typical particle size of about $30 \mu \mathrm{m}$. The morphology of the powder is shown in Fig. 1. In Table 1, typical impurities in Si powder are presented. The substrate material is graphite that has quite high melting point and low thermal expansion coefficient

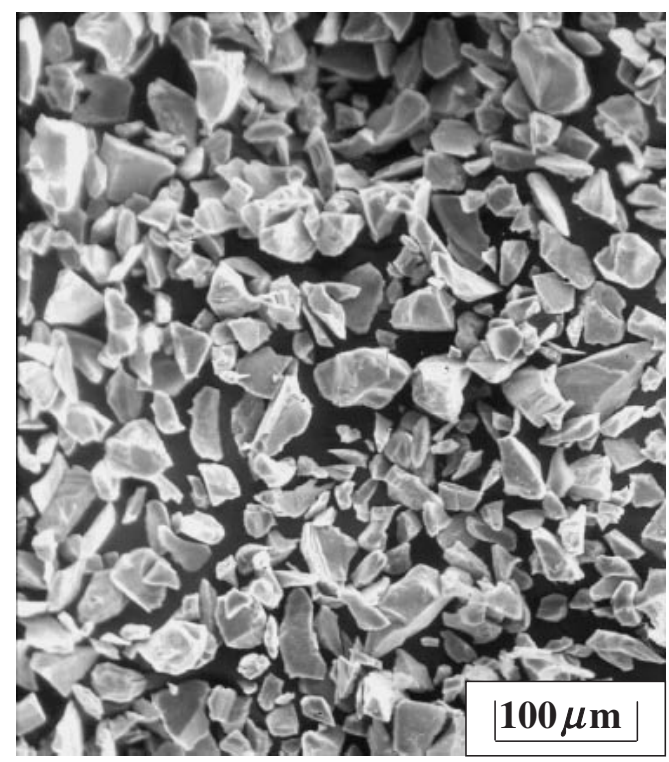

Fig. 1 Morphology of Si powder. 
Table 1 Content of impurities of Si powder.

\begin{tabular}{cccc}
\hline \multicolumn{4}{c}{ Element $($ mass\%) } \\
\hline $\mathrm{O}$ & $\mathrm{Al}$ & $\mathrm{Fe}$ & $\mathrm{Ca}$ \\
2.02 & 0.75 & 0.72 & 0.36
\end{tabular}

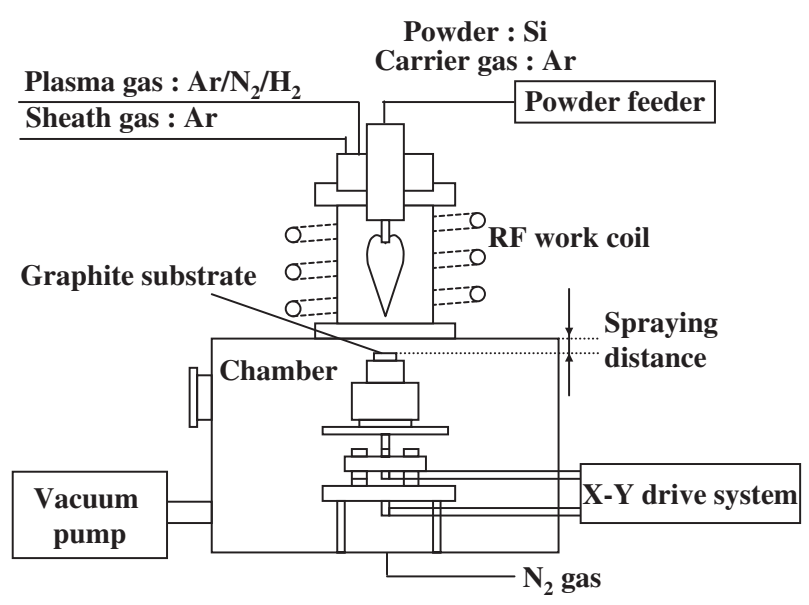

Fig. 2 Schematic diagram of RF plasma equipment.

similar to $\mathrm{Si}$ and $\mathrm{Si}_{3} \mathrm{~N}_{4} \cdot{ }^{14,15)}$ All experiments were carried out with a reactive RF plasma spraying apparatus as shown in Fig. 2. The substrate temperature was measured by an R type thermocouple placed on to the back surface of the substrate. Table 2 indicates the typical spraying parameters in RF plasma spraying. Spraying time was 10 minutes for all experiments after pre-heating the substrates for 5 minutes and the temperature reached approximately to $1300 \mathrm{~K}$. The substrates were reciprocated during spraying using $\mathrm{X}-\mathrm{Y}$ drive system to form uniform thickness coatings onto the substrates. The chamber was once evacuated to a pressure less than $13.3 \mathrm{~Pa}$ using a vacuum pump before the plasma generation. The existence of $\mathrm{Si}_{3} \mathrm{~N}_{4}$ in deposited coatings was verified by X-ray diffraction (XRD) with $\mathrm{Cu} K_{\alpha}$ radiation. Cross section microstructures of the coatings were investigated by scanning electron microscope (SEM) and the energy dispersive X-ray (EDX) was used for the elemental analysis. Cross-section micro hardness was determined by a micro Vickers hardness tester.

\section{Results and Discussion}

\subsection{Plasma spraying of $\mathrm{Si}$ with $\mathrm{Ar} / \mathrm{N}_{2}$ or $\mathrm{Ar} / \mathrm{N}_{2} / \mathrm{H}_{2}$ mixed gas}

First of all, reactive RF plasma spraying of Si powder with $\mathrm{Ar} / \mathrm{N}_{2}$ plasma gas was conducted to verify the possibility of $\mathrm{Si}_{3} \mathrm{~N}_{4}$ forming by this process. Figure 3 shows a typical cross-section microstructure of the coating obtained by the spraying with $\mathrm{Ar} / \mathrm{N}_{2}$ plasma onto graphite substrate. The result indicates that fairly thick coating more than $2 \mathrm{~mm}$ was fabricated with porous microstructure. XRD spectrum of the coating shown in Fig. 4 shows that the coating did not include the nitride phase. It was composed of pure $\mathrm{Si}$ which used for the raw material. The fact that a moderate heat treatment of the coating promotes the nitridation has been
Table 2 Spraying conditions to fabricate $\mathrm{Si}_{3} \mathrm{~N}_{4}$ coatings.

\begin{tabular}{cc}
\hline RF power & $3.4 \sim 10.0 \mathrm{~kW}$ \\
\hline Pr: $10.0 \ell / \mathrm{min}$ \\
Plasma gas flow rate & $\mathrm{N}_{2}: 1.0 \sim 4.0 \ell / \mathrm{min}$ \\
Sheath gas flow rate & $\mathrm{H}_{2}: 0 \sim 1.0 \ell / \mathrm{min}$ \\
Spray distance & Ar: $10 \ell / \mathrm{min}$ \\
Chamber pressure & $20 \mathrm{~mm}$ \\
\hline
\end{tabular}
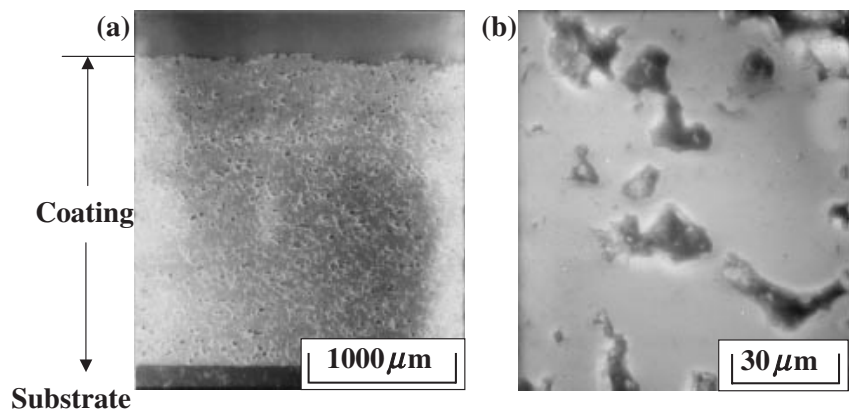

Fig. 3 SEM images of the coating obtained by $\mathrm{Ar} / \mathrm{N}_{2}$ plasma. Ar: $10 \ell /$ min, $\mathrm{N}_{2}: 1.0 \ell / \mathrm{min}$. (a) Cross section micrograph of the coating, (b) microstructure of the coating.

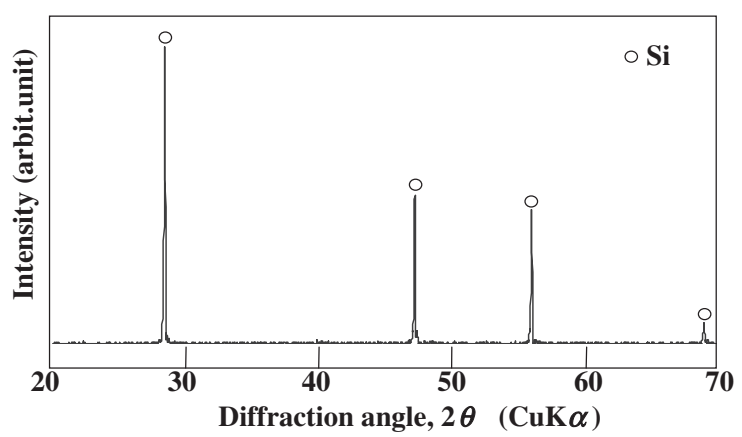

Fig. 4 XRD spectrum of the coating obtained by Ar/ $\mathrm{N}_{2}$ plasma. Ar: $10 \ell /$ $\min , \mathrm{N}_{2}: 1.0 \ell / \mathrm{min}$.

reported. ${ }^{6,14,15)}$ Therefore, $\mathrm{N}_{2}$ plasma radiation to the coating was applied for 10 minutes after the deposition. However, any nitride phases were not detected after the radiation. It was found that silicon nitride could not be formed with $\mathrm{Ar} / \mathrm{N}_{2} \mathrm{RF}$ plasma spraying and plasma radiation after the deposition.

It is well known that $\mathrm{H}_{2}$ addition to plasma enhance the nitridation. Hence, coating was fabricated by the spraying with $\mathrm{Ar} / \mathrm{N}_{2} / \mathrm{H}_{2}$ plasma. XRD spectrum of the coating formed by $\mathrm{Ar} / \mathrm{N}_{2} / \mathrm{H}_{2}$ plasma is shown in Fig. 5. The spectrum shows that the coating is composed of $\mathrm{Si}, \alpha-\mathrm{Si}_{3} \mathrm{~N}_{4}$ and $\beta-\mathrm{Si}_{3} \mathrm{~N}_{4}$ phases. That result indicates that it is possible to fabricate $\mathrm{Si} /$ $\mathrm{Si}_{3} \mathrm{~N}_{4}$ composite coating by reactive RF plasma spraying by adding $\mathrm{H}_{2}$ into plasma. Cross section microstructure of the coating is shown in Fig. 6. Thick and dence coating with lamellar structure was fabricated on the graphite substrate. The deposition rate of the coating can be estimated as about $20 \mu \mathrm{m} / \mathrm{min}$. Hereby, $\mathrm{Si} / \mathrm{Si}_{3} \mathrm{~N}_{4}$ coating having enough thickness and high density could be fabricated by the reactive RF plasma spraying with $\mathrm{Ar} / \mathrm{N}_{2} / \mathrm{H}_{2}$ mixed gas. The mechanical 


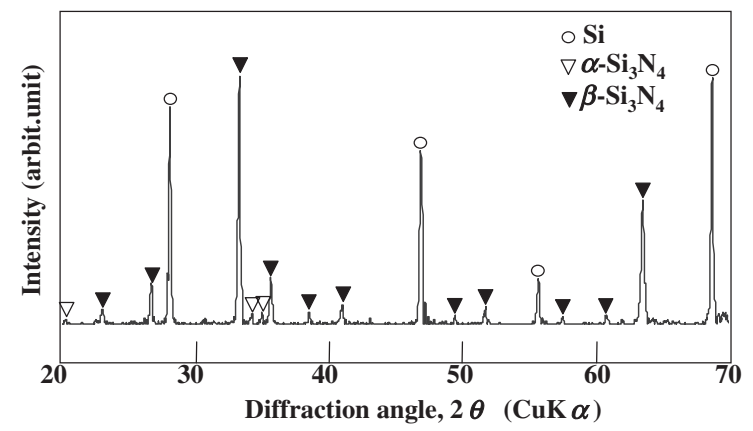

Fig. 5 XRD spectrum of the coating obtained by $\mathrm{Ar} / \mathrm{N}_{2} / \mathrm{H}_{2}$ plasma. Ar: $6 \ell / \mathrm{min}, \mathrm{N}_{2}: 3.0 \ell / \mathrm{min}$ and $\mathrm{H}_{2}: 0.4 \ell / \mathrm{min}$.

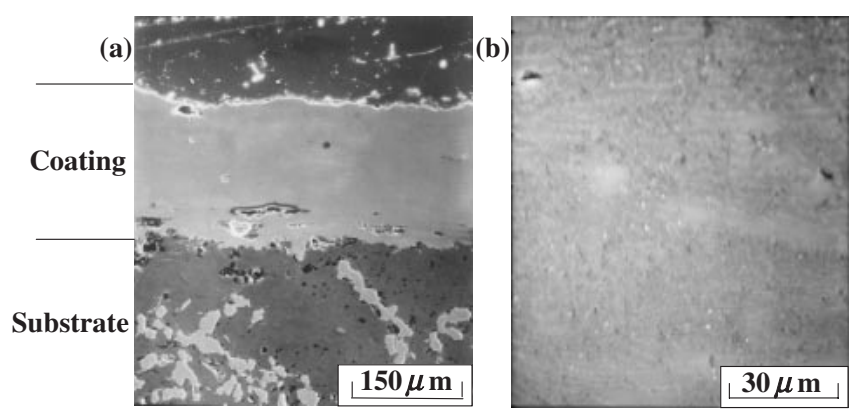

Fig. 6 SEM images of the coating obtained by $\mathrm{Ar} / \mathrm{N}_{2} / \mathrm{H}_{2}$ plasma. Ar: $6 \ell /$ min, $\mathrm{N}_{2}: 3.0 \ell / \mathrm{min}$ and $\mathrm{H}_{2}: 0.4 \ell / \mathrm{min}$. (a) Cross section micrograph of the coating, (b) microstructure of the coating.

property of the coatings was evaluated by a micro Vickers hardness tester. The hardness of pure Si coating obtained by $\mathrm{Ar} / \mathrm{N}_{2} \mathrm{RF}$ plasma spraying was $950 \mathrm{Hv}$. Pure $\beta-\mathrm{Si}_{3} \mathrm{~N}_{4}$ sintering was about $1800 \mathrm{Hv}$. The hardness of the coating obtained by with $\mathrm{Ar} / \mathrm{N}_{2} / \mathrm{H}_{2}$ reactive $\mathrm{RF}$ plasma spraying was $1390 \mathrm{Hv}$. Hereby, the higher hardness of $\mathrm{Si} / \mathrm{Si}_{3} \mathrm{~N}_{4}$ composite coating was realized by the reactive RF plasma spraying.

\subsection{Role of plasma gas fraction on nitridation}

To control the formation degree of the nitride with reactive RF plasma spray process, it is necessary to verify the domination in the nitriding process, such as a plasma gas, RF power, spray distance, spray time or chamber pressure, ${ }^{14,15}$ ) etc. Among these, the role of $\mathrm{H}_{2}$ addition into plasma gas was mainly observed in this research. Figure 7 shows the relationship between intensity ratio of XRD spectra and plasma gas fraction. $\mathrm{N}_{2}$ flow rate was changed with $\mathrm{H}_{2}$ flow rate of $0.4 \ell / \mathrm{min}$, and $\mathrm{H}_{2}$ fraction was changed with $\mathrm{N}_{2}$ flow rate of $4.0 \ell / \mathrm{min}$. The results indicate that the intensity ratio of $\beta-\mathrm{Si}_{3} \mathrm{~N}_{4}$ to those of all other phases increased with increasing $\mathrm{N}_{2}$ or $\mathrm{H}_{2}$ fraction. It is found that both $\mathrm{N}_{2}$ and $\mathrm{H}_{2}$ fraction in the plasma gas could control the nitridation of $\mathrm{Si}$ in RF plasma spray process.

It is considered that the increase of $\mathrm{N}_{2}$ fraction in the plasma gas increases the active species like $\mathrm{N}$ atom, ${ }^{18)}$ which contribute to the nitridation. Thus, increasing of $\mathrm{N}_{2}$ fraction was useful for the increasing of nitride phase in the coating. On the other hand, $\mathrm{H}_{2}$ addition into plasma gas was also effective to fabricate $\mathrm{Si}_{3} \mathrm{~N}_{4}$ phase in reactive $\mathrm{RF}$ plasma spray process. There are many reports on the role of hydrogen

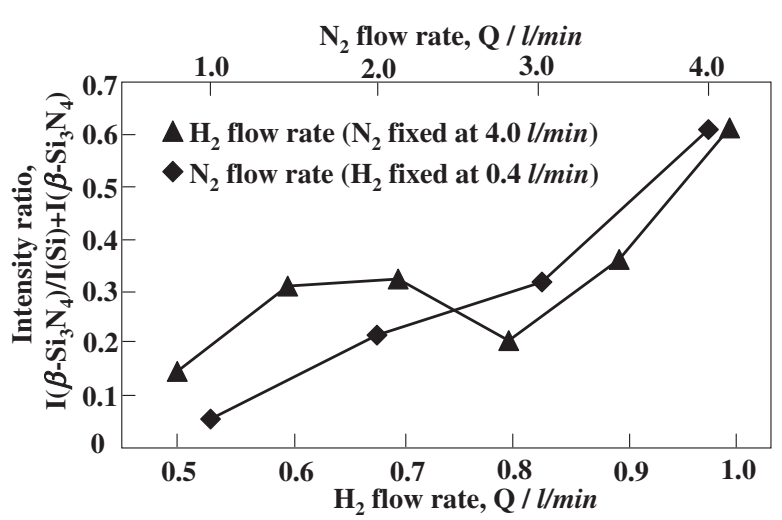

Fig. 7 Relation between intensity ratio of $\mathrm{I}\left(\beta-\mathrm{Si}_{3} \mathrm{~N}_{4}\right) / \mathrm{I}(\mathrm{Si})+\mathrm{I}\left(\beta-\mathrm{Si}_{3} \mathrm{~N}_{4}\right)$ and $\mathrm{H}_{2}$ and $\mathrm{N}_{2}$ flow rates.
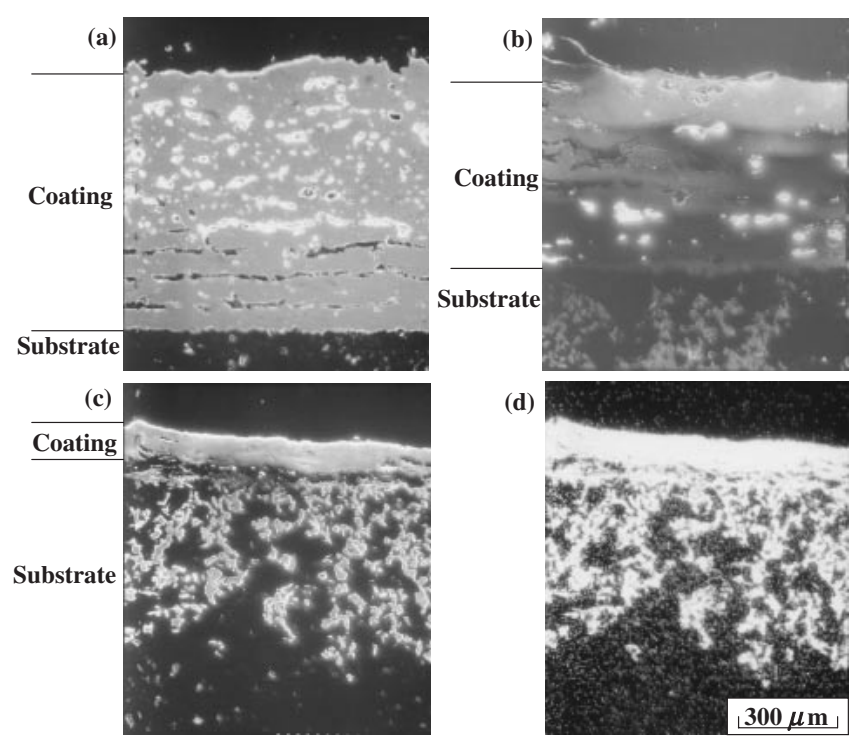

(d)

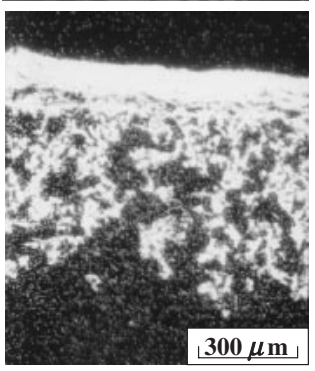

Fig. 8 SEM and EDX images of the coatings. (a) $\mathrm{Ar} / \mathrm{N}_{2} / \mathrm{H}_{2}: 6.0 / 3.0 /$ $0.1 \ell / \mathrm{min}$, (b) $\mathrm{Ar} / \mathrm{N}_{2} / \mathrm{H}_{2}: 6.0 / 3.0 / 0.3 \ell / \mathrm{min}$, (c) $\mathrm{Ar} / \mathrm{N}_{2} / \mathrm{H}_{2}: 6.0 / 3.0 /$ $0.5 \ell / \mathrm{min}$, (d) EDX image of $\mathrm{Si}$.

addition on the nitriding process. Some of them suggest that hydrogen removes an oxide layer on the silicon particles ${ }^{14,19)}$ or generates $\mathrm{NH}$ radicals in plasma which contribute to the nitriding. ${ }^{1,20)}$ The other has pointed out that hydrogen addition just increase the substrate temperature. ${ }^{5)}$

Figure 8 shows the cross section microstructures of the coatings with changing $\mathrm{H}_{2}$ fraction in plasma. It is found from the figures that increase of $\mathrm{H}_{2}$ flow rate brought about the decrease in the coating thickness and densification of the coating structure. In addition, EDX image as shown in Fig. 8(d) indicates that Si diffused into the substrate. Therefore, it was considered that the coatings were once melted on the substrate by $\mathrm{H}_{2}$ addition to the plasma gas. Furthermore, the thermocouple was also melted in this experiment. Hereby, it can be considered that temperature increasing of the substrate surface above melting point of Si $(1700 \mathrm{~K})$ was attained by $\mathrm{H}_{2}$ addition to plasma. However, measuring plasma temperature by spectroscope indicated that $\mathrm{H}_{2}$ addition did not increase the plasma temperature significantly. On the other hand, adding $\mathrm{H}_{2}$ to plasma improve the 


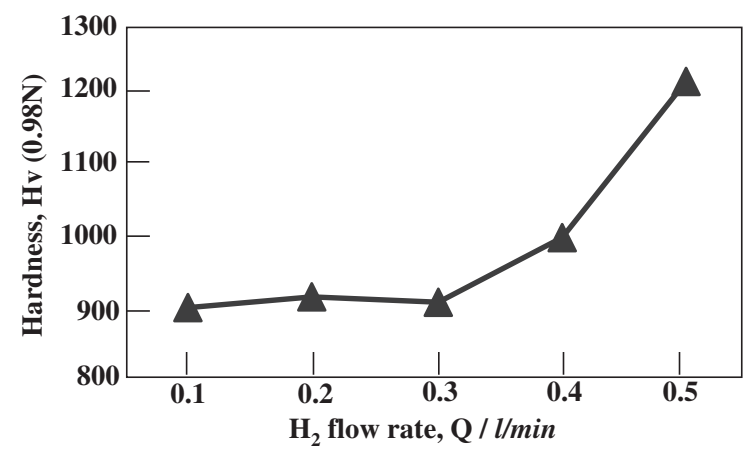

Fig. 9 Relation between micro Vickers hardness and $\mathrm{H}_{2}$ fraction in the plasma gas.

thermal conductivity of plasma ${ }^{21)}$ and increase the RF power (increasing about $8.5 \mathrm{~kW}$ to $10 \mathrm{~kW}$ with adding $5 \ell / \mathrm{min}$ of $\mathrm{H}_{2}$ ). Thus, it was expected that increasing $\mathrm{H}_{2}$ fraction in the plasma gas increased the particles and substrate temperature, which contribute to the nitriding.

Increasing $\mathrm{H}_{2}$ fraction in plasma gas promotes the nitriding of the coating, and formation of nitride may improve the coating hardness. The relationship between $\mathrm{H}_{2}$ fraction in plasma and micro Vickers hardness of the coating was investigated. The results were shown in Fig. 9, and it was clear that the hardness of the coating increased with increasing $\mathrm{H}_{2}$ fraction in the plasma gas. The result indicates that the promotion of $\mathrm{Si}$ nitridation due to the $\mathrm{H}_{2}$ fraction increasing in plasma caused the increasing of coating hardness.

\subsection{Nitridation mechanism of $\mathrm{Si}$}

XRD spectrum of $\mathrm{Si} / \mathrm{Si}_{3} \mathrm{~N}_{4}$ composite coating, as shown in Fig. 5, indicates that the peak intensities of $\beta-\mathrm{Si}_{3} \mathrm{~N}_{4}$ are higher than that of $\alpha-\mathrm{Si}_{3} \mathrm{~N}_{4}$. The formation mechanism of $\beta$ $\mathrm{Si}_{3} \mathrm{~N}_{4}$ has been suggested in some references, ${ }^{14,15,22,23)}$ which indicate that liquid $\mathrm{Si}$ reacts with gaseous nitrogen. Nitride formation of current reactive RF plasma spraying was investigated both on in-flight particles in the plasma and on the deposits on the substrate. Both of them could be formed as liquid phase of Si. Nitridation of the particle after deposition onto the substrate surface was already suggested in 3.2, as the melting of the coating occurred during spraying. To investigate the in-flight nitridation of Si particle, particles were collected by the special collecting apparatus shown in Fig. 10. The apparatus has an inclined ceramic tube, into which Si particles were sprayed. If the silicon particles were fully melted and liquid condition, the particles deposited onto the inside wall of the tube. If the particles were solid condition, they did not deposit on the tube wall and were collected in the basket installed under the tube. Si particles were sprayed with the conditions of $\mathrm{Ar} / \mathrm{N}_{2} / \mathrm{H}_{2}$ : 10/4.0/0.4 $\ell /$ min which was able to fabricate $\mathrm{Si} / \mathrm{Si}_{3} \mathrm{~N}_{4}$ composite coating.

XRD spectrum of the collected particles was shown in Fig. 11. There are no nitride peaks in the figure. The result indicates that effective nitriding reaction did not occur on inflight stage in the plasma in the case of Si particles. RF plasma spraying is characterized as the process which gives

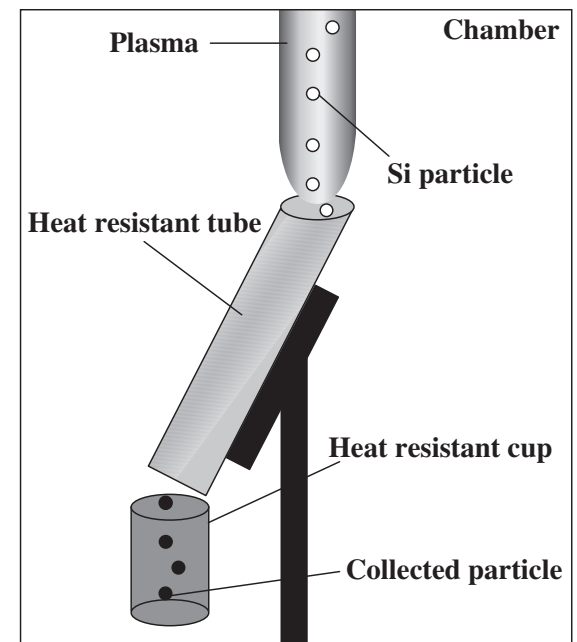

Fig. 10 Schematic diagram of particle collector.

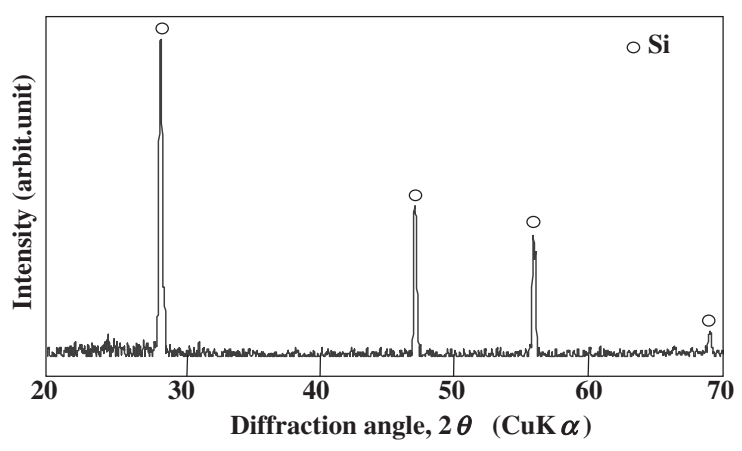

Fig. 11 XRD spectrum of the collected particles.

the higher chance in the reaction due to the longer residence period of the powder particles in the reactive plasma. However, the reaction time of the particles in the plasma is extremely shorter than that after the deposition onto the substrate. Hereby, it was verified that the effective nitriding reaction of Si mainly occurred after the deposition onto the substrate with liquid phase.

\section{Conclusions}

$\mathrm{Si} / \mathrm{Si}_{3} \mathrm{~N}_{4}$ composite coatings on the graphite substrate were fabricated by reactive RF plasma spray process with $\mathrm{H}_{2}$ addition into plasma gas. The coatings were thick and dense with lamellar structure. Furthermore, the coatings have higher hardness fabricated with high deposition rate.

The nitriding of the coatings was controlled by changing $\mathrm{N}_{2}$ and $\mathrm{H}_{2}$ fraction in the plasma gas. It can be considered that increasing $\mathrm{H}_{2}$ fraction in plasma gas increased the substrate temperature, and increasing $\mathrm{N}_{2}$ fraction in plasma gas could also improve nitriding, which increased active species in plasma. Nitriding reaction of $\mathrm{Si}$ in reactive $\mathrm{RF}$ plasma spraying was occurred after deposited onto the substrate. The liquid phase of $\mathrm{Si}$ on the substrate was formed by $\mathrm{H}_{2}$ addition into plasma gas, and reacted with gaseous nitrogen. 


\section{Acknowledgment}

The authors would like to acknowledge K. Takahashi and R. Kikuchi of Tosoh Corporation for analysis of Si powder.

\section{REFERENCES}

1) Y. Ando, S. Tobe, H. Tahara and T. Yoshikawa: ISIJ Int. 42 (2002) 1371-1375.

2) I. Bertoti: Surf. Coatings Technol. 151-152 (2002) 194-203.

3) S. Chatterjee, S. Chandrashekhar and T. S. Sudarshan: J. Mater. Sci. 27 (1992) 3409-3423.

4) H. E. Rebenne and D. G. Bhat: Sruf. Coatings Technol. 60 (1994) 1-13.

5) B. O. Johansson, J. E. Sundgren, J. E. Greene, A. Rockett and S. A. Barnett: J. Vac. Sci. Technol. A, 3-2 (1985) 303-307.

6) M. Fukumoto, S. Itoh and S. Itoh: Surf. Engineering 13-4 (1997) 315319.

7) A. Barata, L. Cunha and C. Moura: Thin Solid Films 398-399 (2001) 501-506.

8) Y. Tsunekawa, M. Okumiya, T. Kobayashi, M. Okuda and M. Fukumoto: J. Thermal Spray Technol. 5-2 (1996) 139-144.

9) J. G. Heinrich and H. Kruner: Tailoring of Mechanical Properties of $\mathrm{Si}_{3} \mathrm{~N}_{4}$ Ceramics, ed. by M. J. Hoffmann and G. Petzow. Kluwer, (Academic Publishers, 1994) pp. 19-41.
10) S. R. Choi and J. A. Salem: J. Am. Ceram. Soc. 77 (1994) 1042-1046.

11) H. Takahashi, N. Shinohara, K. Uematsu and T. Junichiro: J. Am. Ceram. Soc. 79 (1996) 843-848.

12) I. N. Mihailescu, A. Lita, V. S. Teodorescu, A. Luches, M. Martino, A. Perrone and M. Gartner: J. Mater. Sci. 31 (1996) 2839-2847.

13) S. Yan, H. Maeda, J. I. Hayashi, K. Kusakabe, S. Morooka and T. Okubo: J. Mater. Sci. 28 (1993) 1829-1833.

14) T. Eckardt, W. Mallener and D. Stover: VDI BERICHTE 1166 (1995) 341-348.

15) T. Eckardt, W. Mallener and D. Stover: Proc. 7th National Thermal Spray Conference, (1994) pp. 515-519.

16) S. Thiele, R. B. Heimann, L. M. Berger, M. Herrmann, M. Nebelung, T. Schnick, B. Wielage and P. Vuoristo: J. Thermal Spray Technol. 112 (2002) 218-225.

17) A. Utsumi, J. Matsuda, M. Yoneda, M. Katsumura and T. Araki: Proc. ITSC'95, (1995) pp. 325-330.

18) M. Tamaki, Y. Tomii, N. Yamamoto, H. Kuwabara and I. Nishikawa: Journal of the Japan Society of Powder and Powder Metallurgy 44 (1997) 712-715

19) H. Dervisbegovic and F. L. Riley: J. Mater. Sci. 16 (1981) 1945-1955.

20) O. Matsumoto, M. Konuma and Y. Kanzaki: J. Less-Common Met. 84 (1982) 157-163.

21) E. Bourdin, P. Fauchais and M. Boulos: Int. J. Heat Mass Transfer. 26 (1983) 567-582.

22) A. J. Moulson: J. Mater. Sci. 14 (1979) 1017-1051.

23) H. M. Jennings: J. Mater. Sci. 18 (1983) 951-967. 